\title{
PENGARUH TRUST TERHADAP TAX AVOIDANCE
}

\author{
Meco Sitardja ${ }^{1}$, Waluyo ${ }^{2}$ \\ ${ }^{1}$ Universitas Agung Podomoro, ${ }^{2}$ Universitas Mercu Buana \\ Jalan Letjen S. Parman Kav 28 Jakarta 11470 \\ meco.sitardja@podomorouniversity.ac.id
}

\begin{abstract}
This study analyzes the effect of Trust in government on Tax Avoidance. This research is based on agency theory where the Tax Institution as the agent and Taxpayer as the principal. This study uses 80 samples of non-financial sector companies listed on the Indonesia Stock Exchange in 2019 with a purposive sampling method. The analysis uses multiple regression to see the effect of General Trust, Ability, Benevolence and Integrity on Tax Avoidance. Empirical results show that General Trust, Ability and Benevolence have a positive effect on Tax Avoidance. On the other hand, Integrity does not have an influence because it is considered as an abstract factor for taxpayers to determine their attitude to comply with taxes or avoid taxes. The research implication for Tax Institution is the need to increase disclosure of information related to tax benefits for the public so that the Director General of Taxes can be considered as a Wealth Agent for all taxpayers. For further research, research can be developed Social Norm factors on tax avoidance because it becomes a strong impetus for individuals and companies to behave in relation to tax avoidance.
\end{abstract}

Keywords : trust, tax avoidance, agency theory

\begin{abstract}
Abstrak
Penelitian ini menganalisa pengaruh Trust in government terhadap Tax Avoidance. Penelitian ini didasarkan atas teori keagenan dimana Dirjen Pajak selaku pihak agen dan Wajib Pajak selaku prinsipal. Penelitian ini menggunakan 80 sampel perusahaan sektor non keuangan yang terdaftar di Bursa Efek Indonesia pada tahun 2019 dengan metode purposive sampling. Analisa menggunakan regresi berganda untuk melihat pengaruh General Trust, Ability, Benevolence dan Integrity terhadap Tax Avoidance. Hasil empiris menunjukkan bahwa General Trust, Ability dan Benevolence berpengaruh secara positif terhadap Tax Avoidance. Di lain pihak, Integrity tidak memilki pengaruh karena dianggap sebagai abstract factor bagi para wajib pajak untuk menentukan sikap dalam mematuhi pajak atau menghindari pajak. Implikasi penelitian bagi Dirjen Pajak adalah perlu peningkatan pengungkapan informasi terkait manfaat pajak bagi masyarakat sehingga Dirjen Pajak dapat dianggap sebagai Wealth Agent bagi semua Wajib Pajak. Untuk penelitian selanjutnya, penelitian dapat dikembangkan faktor Social Norm terhadap penghindaran pajak karena menjadi dorongan yang kuat bagi pribadi maupun perusahaan untuk bersikap terkait dengan penghindaran pajak.
\end{abstract}

Kata kunci: trust, penghindaran pajak, teori keagenan

\section{Pendahuluan}

Menurut data pengadilan pajak (20132018), jumlah permohonan banding yang diajukan oleh WP bertambah dimana tahun 2013 sebanyak 5.217 kasus; tahun 2014 sebanyak 7.386 kasus; tahun 2015 sebanyak 7.669 kasus; tahun 2016 sebanyak 7.109 kasus; tahun 2017 sebanyak 5.553 kasus; dan tahun 2018 sebanyak 7.813 kasus. Perincian data ini menunjukkan semakin tingginya keengganan WP untuk dikenakan denda pajak dari proses pemeriksaan DJP. Pertambahan jumlah kasus pemeriksaan pajak yang diajukan banding pada pengadilan pajak menunjukkan indikasi keengganan WP melakukan pembayaran pajak dengan benar.

Di lain pihak, data komite pengawasan pajak (2019) menunjukkan bahwa jumlah pengaduan masyarakat baik individu maupun organisasi independen terhadap Direktorat Jenderal Pajak (DJP) mengalami tren penurunan dari tahun 2016 sampai tahun 2018 
dimana tahun 2016 sebanyak 114 pengaduan; tahun 2017 sebanyak 77 pengaduan; dan tahun 2018 sebanyak 60 pengaduan. Tren positif ini menunjukkan adanya peningkatan trust terhadap otoritas pajak yaitu Dirjen Pajak.

Menurut Siahaan (2012), trust merupakan salah satu faktor yang mempengaruhi tingkat kepatuhan pajak. Nazier (2016) menyatakan bahwa kurangnya tingkat kepercayaan masyarakat Indonesia menjadi penyebab rendahnya kesadaran untuk membayar pajak. Hal ini diperkuat oleh pernyataan Jokowi (2016) yang menyatakan bahwa pemerintah harus berorientasi pada membangun trust, sehingga kesadaran dari masyarakat untuk membayar pajak meningkat. Karena itu, orientasi pemerintah sekarang membangun trust. Hal yang sama disampaikan oleh Darmin Nasution (2015) yaitu target penerimaan pajak dapat tercapai apabila ada kepercayaan wajib pajak dan aparat.

Penelitian ini didasarkan atas teori legitimasi dimana adanya tindakan legitimasi dari Dijen Pajak dalam rangka mendapatkan reputasi positif di mata wajib pajak. Reputasi yang positif yang menciptakan trust wajib pajak karena berasal dari kumpulan pengalaman masa lalu yang terkait dengan Dirjen Pajak. Trust-as-heuristic theory menjabarkan bahwa individu akan menentukan pola keputusan untuk memilih mendukung aktivitas pemerintah (Hetherington, 2005) dalam Jimenez (2013). Ini berarti bahwa ketika individu menganggap pemerintah dapat dipercaya, maka mereka akan mendukung aktivitas pemerintah dan sebaliknya. Kepercayaan kepada pemerintah juga memiliki konsekuensi yang positif dimana salah satunya adalah peningkatan kepatuhan pajak atau dengan kata lain, adanya keengganan dalam melakukan penghindaran pajak. Hal ini karena penghindaran pajak adalah rekayasa tax affairs yang masih tetap berada dalam bingkai ketentuan perpajakan (lawfu).

\section{Teori Legitimasi}

Menurut Lindblom (1994), legitimasi adalah suatu kondisi atau status yang terjadi ketika suatu sistem nilai suatu entitas sesuai dengan sistem nilai dari sistem sosial yang lebih besar, tempat entitas tersebut berada. Teori legitimasi menjabarkan adanya upaya mencari legalitas dari aktivitas yang dilakukan oleh organisasi. Legalitas dapat diartikan bahwa aktivitas organisasi selain mendapatkan dukungan dari undang-undang yang berlaku di negara, juga mendapatkan dukungan dari masyarakat sekitar berupa partispasi yang dilakukan masyarakat dan tidak terhambatnya organisasi dalam beroperasi melalui memenuhi harapan masyarakat yaitu bertindak sesuai dengan aturan dan nilai-nilai sosial di dalam lingkungan masyarakat (Freedman and Jaggi, 2005).

\section{Trust}

Trust adalah keinginan satu pihak untuk percaya kepada pihak yang lain berdasarkan harapan bahwa pihak tersebut akan melakukan sesuatu yang tepat kepada pemberi kepercayaan tanpa tergantung pada kemampuannya untuk mengawasi dan mengendalikannya (Mayer et al., 1995). Menurut Lewis and Weigert (1985), trust terdiri atas tiga dimensi yaitu kognitif, afeksi dan behavior. Sedangkan, menurut Mayer et al. (1995) ada tiga faktor yang membentuk kepercayaan seseorang terhadap orang lain yaitu kemampuan (ability), kebaikan hati (benevolence), dan integritas (integrity). Ketiga faktor tersebut dapat dijabarkan sebagai berikut:

a. Kemampuan (Abillty). Kemampuan mengacu pada kompetensi dan karakteristik organisasi dalam mempengaruhi dan mengotorisasi wilayah yang spesifik. Kim and Tadisina. (2003) menyatakan bahwa ability meliputi kompetensi, pengalaman, pengesahan instansional, dan kemampuam dalam ilmu pengetahuan.

b. Kebaikan hati (Benevolence). Kebaikan hati merupakan kemauan organisasi dalam memberikan kepuasan yang saling menguntungkan antara dirinya dengan konsumen. Profit yang diperoleh organisasi dapat dimaksimumkan, tetapi kepuasan konsumen juga tinggi. Menurut Kim and Tadisina (2003), benevolence meliputi perhatian, empati, keyakinan, dan daya terima.

c. Integritas (Integrity). Integritas berkaitan dengan bagaimana perilaku atau kebiasaan organisasi dalam menjalankan bisnisnya. 
Informasi yang diberikan kepada konsumen apakah benar sesuai dengan fakta atau tidak. Kualitas produk yang dijual apakah dapat dipercaya atau tidak. Kim and Tadisina (2003) mengemukakan bahwa integrity dapat dilihat dari sudut kewajaran (fairness), pemenuhan (fulfillment), kesetiaan (loyalty), keterus-terangan (honestly), keterkaitan (dependability), dan kehandalan (reliabilty).

\section{Tax Avoidance}

Penghindaran pajak adalah rekayasa 'tax affairs' yang masih tetap berada dalam bingkai ketentuan perpajakan (lawfu). Penghindaran pajak dapat terjadi didalam bunyi ketentuan atau tertulis di undang-undang dan berada dalam jiwa dari undang-undang atau dapat juga terjadi dalam bunyi ketentuan undang-undang tapi berlawanan dengan jiwa undang-undang. Komite urusan fiskal dari Organization for Economic Coorperation and Development (OECD) dalam Suandy (2016) menyebutkan ada tiga karakter penghindaran pajak sebagai berikut:

1. Adanya unsur artifisial di mana berbagai pengaturan seolah-olah terdapat di dalamnya padahal tidak, dan ini dilakukan karena ketiadaan faktor pajak.

2. Skema semacam ini sering memanfaatkan loopsholes dari undang-undang atau menerapkan ketentuan-ketentuan legal untuk berbagai tujuan, padahal bukan itu yang sebetulnya dimaksudkan oleh pembuat undang-undang.

3. Kerahasiaan juga sebagai bentuk dari skema ini di mana umumnya para konsultan menunjukan alat atau cara untuk melakukan penghindaran pajak dengan syarat Wajib Pajak menjaga serahasia mungkin (Council of Executive Secretaries of Tax Organżations, 1991).

\section{Penelitian Terdahulu}

Sitardja dan Dwimulyani (2016) menganalisa pengaruh Good Public Governance terhadap Tax Compliance melalui Trust. Hasil penelitian menunjukkan bahwa keadilan pajak terbukti berpengaruh positif terhadap trust in government dalam dimensi general fairness dan exchange fairness (Sitardja \& Dwimulyani, 2016). Selain itu, trust akan mendorong sikap positif terhadap instansi pajak sehingga berdampak kepada kepatuhan pajak secara sukarela. Hantoyo, dkk (2016) menganalisa pengaruh penghindaran pajak dan sanksi perpajakan terhadap kepatuhan wajib pajak. Hasil menunjukkan bahwa Penghindaran Pajak berpengaruh tidak signifikan dan Sanksi perpajakan berpengaruh signifikan secara parsial terhadap Kepatuhan Wajib Pajak. Namun secara simultan, Penghindaran Pajak dan Sanksi Perpajakan terbukti signifikan terhadap Kepatuhan Pajak.

\section{Pengembangan Hipotesis \\ Pengaruh General Trust terhadap Tax Avoidance}

Trust didefinisikan sebagai kesediaan suatu pihak untuk menjadi rentan terhadap tindakan pihak lain. Ketika ada trust, maka dapat terlihat dalam perilaku pengambilan risiko (Mayer et al, 1995). Oleh karena itu, tingkat kepercayaan yang lebih rendah biasanya terkait dengan perilaku pengambilan risiko yang lebih sedikit, dan dapat mengakibatkan berkurangnya tingkat keterlibatan dalam aktivitas yang menurut pengamat berisiko.

General Trust terbentuk dari reputasi yang dilihat dari pengalaman masa lalu dari pihak ketiga (Afzal et al., 2010). Reputasi yang baik akan mengarahkan pada harapan yang positif tetapi reputasi yang buruk dapat mengarahkan pada citra buruk suatu merek (Creed and Miles, 1996).

Dengan kata lain, reputasi yang positif akan membentuk trust yang positif sehingga mendorong keengganan WP dalam melakukan penghindaran pajak. Sebaliknya, tingkat penghindaran pajak akan lebih tinggi. Dikarenakan pajak merupakan biaya bagi perusahaan dan pemilik perusahaan (Chen et al, 2010), sehingga wajib pajak akan lebih memilih melakukan tindakan yang tidak berisiko atau tidak merugikan yaitu aggresive tax avoidance.

H1: General Trust berpengaruh secara negatif terhadap Tax Avoidance

\section{Pengaruh Abilty terhadap Tax Avoidance} Ability didefinisikan sebagai kumpulan keterampilan, kompetensi dan karakteristik yang memungkinkan suatu pihak untuk memiliki pengaruh dalam beberapa domain 
tertentu (Mayer et al, 1995). Menurut Peraturan Mentri Keuangan Nomor 246/PMK.01/2011 tentang Mekanisme Penetapan Jabatan dan Peringkat Pelaksana di Lingkungan Kementrian Keuangan, kompetensi teknis adalah kemampuan, pengetahuan, dan keterampilan yang dimiliki oleh seorang pelaksana yang terkait dengan bidang tugas pekerjaannya. Fiskus diharapkan memliki kompetensi yaitu pengetahuan (knowledge), keahlian ( $s k i l l)$, dan pengalaman (experience) dalam hal kebijakan perpajakan, administrasi pajak dan perundang - undangan perpajakan.

Berdasarkan penelitian yang dilakukan Pahala, et al (2013) menyimpulkan bahwa kompetensi berpengaruh terhadap kepuasan wajib pajak. Hal ini membuktikan bahwa dengan memiliki pengetahuan akuntansi pajak yang baik pada pegawai pajak, membuat wajib pajak puas atas kinerja yang dilakukan oleh pegawai pajak pada KPP. Dengan kata lain, semakin baik kompetensi fiskus maka wajib pajak akan semakin puas dalam memenuhi kewajiban perpajakan. Tingkat kepuasan wajib pajak akan meningkatkan tingkat trust terhadap Dirjen Pajak sehingga mendorong adanya tindakan kepatuhan pajak yaitu rendahnya tax avoidance yang dilakukan oleh wajib pajak.

H2: Ability berpengaruh secara negatif terhadap Tax Avoidance

\section{Pengaruh Benevolence terhadap Tax Avoidance}

Benevolence didefinisikan sebagai sejauh mana trustee ingin berbuat baik kepada trustor, selain dari motif keuntungan semata (Mayer et al, 1995). Benevolent Organżation adalah organisasi yang tidak hanya memikirkan kepentingannya sendiri tetapi juga mampu menyelaraskan minat ini dengan niat untuk berbuat baik dengan organisasi lain.

Menurut Mahmudi (2007), hubungan pemerintah dan masyarakat digambarkan sebagai hubungan pertanggung jawaban, dimana Pemerintah (agen) harus dapat mempertanggung jawabkan aktivitas dan kinerjanya kepada masyarakat (prinsipal) yang telah memberikan dana kepada Pemerintah. Hal ini dikarenakan tugas utama Pemerintah sebagai sektor publik adalah untuk menciptakan kesejahteraan masyarakat, dimana kesejahteraan masyarakat tidak hanya berupa kesejahteraan fisik yang berupa material saja, melainkan termasuk kesejahteraan non fisik yang bersifat immaterial. Fokus utama dari organisasi sektor publik adalah maksimisasi pelayanan publik.

Oleh karena itu, Dirjen Pajak selaku Otoritas Pajak harus memaksimalkan pelayanan pajak sehingga expected service akan sesuai dengan actual service. Semakin baiknya pembayaran pajak, semakin baik manfaat pajak yang dirasakan oleh wajib pajak. Hal inilah yang mendorong adanya tindakan kepatuhan pajak yaitu rendahnya tax avoidance yang dilakukan oleh wajib pajak.

H3: Benevolence berpengaruh secara negatif terhadap Tax Avoidance

\section{Pengaruh Integrity terhadap Tax Avoidance}

Integrity didefinisikan sebagai persepsi trustor bahwa trustee mematuhi seperangkat prinsip yang masih diterima oleh trustor dimana akan dikaitkan konsistensi tindakan trustee masa lalu, reputasi yang kredibel tentang trustee dari pihak lain, kepercayaan yang terkait dengan tingkat kejujuran yang dimiliki oleh trustee, dan sejauh mana tindakan trustee sesuai dengan perkataannya (Mayer et al, 1995). Suatu organisasi dianggap memiliki integritas ketika menghormati perjanjian yang telah dibuat sebelumnya dengan adanya kesesuaian antara prinsip dan tindakan mereka dengan norma-norma keadilan yang ditetapkan.

Tingkat keberhasilan penerimaan pajak selain dipengaruhi oleh wajib pajak (tax payer), juga dipengaruhi oleh kebijakan perpajakan (tax policy), administrasi perpajakan (tax administration) dan hukum pajak (tax law). Tiga faktor terakhir melekat dan dikendalikan oleh fiskus sendiri. UU No 16 Tahun 2009 tentang ketentuan umum dan tata cara perpajakan pasal 36A mengatur bahwa pegawai pajak tidak dapat bertindak di luar kewenangannya yang telah diatur oleh ketentuan peraturan perundang-undangan perpajakan. Selain itu, pegawai pajak tidak boleh melakukan pemerasan dan pengancaman terhadap wajib pajak dalam hal kepentingannya sendiri. Terakhir, pegawai pajak tidak dapat menyalahgunakan kekuasaannya dengan memaksa seseorang untuk memberikan sesuatu, membayar, dan menerima 
pembayaran, atau mengerjakan sesuatu bagi dirinya sendiri.

Dengan kata lain, kepatuhan wajib pajak dalam memenuhi kewajiban membayar pajak tergantung pada bagaimana sikap petugas pajak. Hal inilah yang mendorong adanya tindakan kepatuhan pajak yaitu rendahnya tax avoidance yang dilakukan oleh wajib pajak.

$\mathrm{H} 4$ : Integrity berpengaruh secara negatif terhadap Tax Avoidance

\section{Metode Penelitian}

\section{Populasi dan Sampel Penelitian}

Dalam penelitian ini,

peneliti menggunakan pengujian hipotesis antara variabel penelitian. Populasi penelitian ini adalah perusahaan-perusahaan di sektor non keuangan (pengecualian perusahaan di sektor keuangan, asuransi dan perbankan) yang telah terdaftar di Bursa Efek Indonesia (BEI) pada periode tahun 2019. Sampel penelitian ini adalah semua perusahaan yang go public yang dipilih berdasarkan metode purposive sampling. Sampel dipilih berdasarkan atas kesesuaian karakteristik dengan kriteria sampel yang ditentukan. Adapun kriteria yang digunakan untuk memilih sampel adalah sebagai berikut :

a. Perusahaan yang terdaftar di Bursa Efek Indonesia di tahun 2019.

b. Perusahaan tidak termasuk perusahaan BUMN dan perusahaan keuangan.

\section{Variabel Operasional}

Variabel yang digunakan dalam penelitian ini dijabarkan di bawah ini:

Tabel 1

Pengukuran Variabel

\begin{tabular}{|c|c|c|c|}
\hline $\begin{array}{l}\text { Fungsi } \\
\text { Variabel }\end{array}$ & $\begin{array}{l}\text { Variabel } \\
\text { Penelitian }\end{array}$ & Skala & Referensi \\
\hline Dependen & Tax Avoidance & Rasio & $\begin{array}{l}\text { Hanlond dan Slemrod } \\
\text { (2009) }\end{array}$ \\
\hline Independen & $\begin{array}{l}\text { General Trust } \\
\text { Ability } \\
\text { Benevolence } \\
\text { Integrity }\end{array}$ & Ordinal & $\begin{array}{l}\text { Mayer et al. (1995); } \\
\text { Benk and Budak } \\
\text { (2012); Sitardja dan } \\
\text { Dwimulyani (2016) }\end{array}$ \\
\hline
\end{tabular}

Sumber : dikembangkan dalam penelitian

\section{Metode Analisis Data}

Metode analisis data yang digunakan dalam penelitian ini adalah analisa regresi berganda yang menggunakan alat statistik SPSS versi 26.0.

Berikut ini adalah model persamaan penelitian:

$Y=a_{0}+a_{1} X_{1}+a_{2} X_{2}+a_{3} X_{3}+a_{4} X_{4}+\varepsilon$

Keterangan:

$\mathrm{a}_{0-4}=$ Koefisien

$\mathrm{X}_{1}=$ General Trust

$\mathrm{X}_{2}=$ Ability

$\mathrm{X}_{3}=$ Benevolence

$\mathrm{X}_{4}=$ Integrity

$\mathrm{Y}=$ Tax Avoidance

$\varepsilon=$ estimasi kesalahan

\section{Hasil Uji Validitas dan Reliabilitas}

Pengujian validitas dilakukan dengan menghitung korelasi antara masing-masing pertanyaan dengan skor total. Analisis ini digunakan untuk mengetahui pernyataan mana yang valid dengan mengacu pada tingkat signifikan sebesar 0,3 ( $r_{s}$ kritis) (Ghozali, 2013). Tabel 3.1 menunjukkan bahwa variabel General Trust (X1), Ability (X2), Benevolence (X3) dan Integrity (X4) terbukti valid karena nilai korelasi $\geq 0,3$.

\section{Tabel 2}

Hasil Uji Validitas Item-Total Statistics

\begin{tabular}{|r|r|r|r|r} 
& $\begin{array}{c}\text { Scale } \\
\text { Mean if } \\
\text { Item } \\
\text { Deleted }\end{array}$ & $\begin{array}{c}\text { Scale } \\
\text { Variance } \\
\text { if Item } \\
\text { Deleted }\end{array}$ & $\begin{array}{c}\text { Corrected } \\
\text { Item-Total } \\
\text { Correlation }\end{array}$ & $\begin{array}{c}\text { Cronbach's } \\
\text { Alpha if } \\
\text { Item } \\
\text { Deleted }\end{array}$ \\
\hline G1 & 6.5500 & 1.415 & .792 & .789 \\
\hline G2 & 6.6625 & 1.492 & .768 & .812 \\
\hline G3 & 6.7375 & 1.614 & .715 & .859 \\
\hline A1 & 6.8875 & 1.899 & .779 & .914 \\
\hline A2 & 6.8375 & 1.809 & .863 & .843 \\
\hline A3 & 6.8000 & 1.884 & .836 & .867 \\
\hline B1 & 3.3375 & .454 & .709 &. \\
\hline B2 & 3.5125 & .481 & .709 &. \\
\hline I1 & 7.0250 & 1.215 & .582 & .560 \\
\hline I2 & 7.2500 & 1.177 & .574 & .562 \\
\hline I3 & 6.9000 & 1.078 & .447 & .742 \\
\hline Sumber.
\end{tabular}

Sumber: SPSS 25.0 
Jurnal Ekonomi : Journal of Economic p-ISSN: 2087-8133 | e-ISSN: 2528-326X

Pengujian reliabilitas dilakukan dengan menghitung Cronbach Alpha (a). Analisis ini digunakan untuk menguji hasil pengukuran relatif konsisten dengan mengacu pada tingkat signifikan Cronbach Alpha diatas 0,7 (Ghozali, 2013). Tabel 3.2 menunjukkan bahwa variabel General Trust (X1), Ability (X2), Benevolence (X3) dan Integrity (X4) terbukti reliable karena nilai Cronbach Alpha $>0,7$.

\section{Tabel 3}

Hasil Uji Reliabilitas

Reliability Statistics

Cronbach's

\begin{tabular}{ccc} 
Variable & Alpha & N of Items \\
\hline General & .874 & 3 \\
Ability & .913 & 3 \\
Benevolenc & .829 & 2 \\
$\mathrm{e}$ & & 3 \\
Integrity & .708 & 3
\end{tabular}

\section{Hasil dan Pembahasan \\ Deskripsi Obyek Penelitian}

Unit analisis dalam penelitian ini adalah perusahaan yang terdaftar di BEI sesuai dengan Fact Book BEI tahun 2019. Total sampel adalah 411 perusahaan, yang diwakili oleh responden dari salah satu anggota manajemen perusahaan, yaitu Corporate Secretary, Manajer Pajak, Kabag Pajak, Manajer Keuangan, dan Direktur. Jadi dengan demikian unit analisis dalam penelitian ini adalah perusahaan. Penelitian ini menggunakan data primer dan data sekunder. Data primer berupa kuesioner terkait indikator Trust, sedangkan data sekunder bersumber dari laporan tahunan perusahaan tahun 2019 yaitu www.idx.co.id.
Tabel 4

Persentase Jumlah Responden Penelitian

\begin{tabular}{|c|c|c|}
\hline \multicolumn{2}{|l|}{ Kriteria } & $\begin{array}{l}\text { Jumlah } \\
\text { Emiten }\end{array}$ \\
\hline \multicolumn{2}{|c|}{$\begin{array}{l}\text { Emiten perusahaan Desember } \\
2014\end{array}$} & 514 \\
\hline \multicolumn{2}{|c|}{ Emiten perusahaan BUMN } & 20 \\
\hline \multicolumn{2}{|c|}{ Emiten perusahaan keuangan } & 83 \\
\hline \multicolumn{2}{|c|}{ Total Sampel Penelitian } & 411 \\
\hline Responden & Jumlah & Persentase \\
\hline Keseluruhan & 411 & $100 \%$ \\
\hline $\begin{array}{ll}\text { Yang } & \text { tidak } \\
\text { menjawab } & \\
\end{array}$ & 331 & $80.54 \%$ \\
\hline Yang menjawab & 80 & $19.46 \%$ \\
\hline
\end{tabular}

Berdasarkan tabel diatas, maka tingkat responsiveness adalah $19.46 \%$ dimana industri Property and Real Estate yang mengembalikan kuesioner, yaitu sebanyak 20 kuesioner kemudian diikuti oleh industri Transportation sebanyak 12 kuesioner; 8 kuesioner dari industri Retail Trade; 9 kuesioner dari industri Tourism, Restaurant \& Hotel, 5 kuesioner dari industri Plantation; 6 kuesioner dari industri Whole sale dan Coal Mining, 3 kuesioner dari industri Plastics \& Packaging; 1 kuesioner dari Advertising Printing \& Media; 2 kuesioner dari Chemicals, 1 kuesioner dari industri Computer \& Services; 2 kuesioner dari Automotive \& Components; 4 kuesioner dari Metal \& Allied Products, 5 kuesioner dari Animal Feed, dan 2 kuesioner Ceramics Glass \& Porcelain.

\section{Tabel 5}

Statistik Deskriptif

Descriptive Statistics

$\mathrm{N}$ Minimum Maximum Mean Std. Deviation

\begin{tabular}{|l|l|l|l|l|l|}
\hline G1 & 80 & 2.00 & 5.00 & 3.4250 & .68943 \\
\hline G2 & 80 & 2.00 & 5.00 & 3.3125 & .66739 \\
\hline G3 & 80 & 2.00 & 4.00 & 3.2375 & .64128 \\
\hline General & 80 & 2.00 & 4.67 & 3.3250 & .59528 \\
\hline A1 & 80 & 2.00 & 5.00 & 3.3750 & .73562 \\
\hline A2 & 80 & 2.00 & 5.00 & 3.4250 & .72522 \\
\hline A3 & 80 & 2.00 & 5.00 & 3.4625 & .71057 \\
\hline Ability & 80 & 2.00 & 5.00 & 3.4208 & .66823 \\
\hline B1 & 80 & 2.00 & 5.00 & 3.5125 & .69344 \\
\hline B2 & 80 & 2.00 & 4.00 & 3.3375 & .67400 \\
\hline
\end{tabular}


Descriptive Statistics

$\mathrm{N}$ Minimum Maximum Mean Std. Deviation

\begin{tabular}{lr|r|r|r|r} 
& \multicolumn{5}{c}{ Descriptive Statistics } \\
& $\mathrm{N}$ & Minimum & Maximum & Mean & Std. Deviation \\
\hline Benevolence & 80 & 2.00 & 4.00 & 3.4250 & .63195 \\
\hline I1 & 80 & 3.00 & 5.00 & 3.5625 & .57023 \\
\hline I2 & 80 & 2.00 & 4.00 & 3.3375 & .59414 \\
\hline I3 & 80 & 2.00 & 5.00 & 3.6875 & .72205 \\
\hline Integrity & 80 & 2.67 & 4.67 & 3.5292 & .50230 \\
\hline Tax Avoidance & 80 & -4.01 & 12.32 & .5725 & 1.97763 \\
\hline Valid N (listwise) & 80 & & & & \\
\hline
\end{tabular}

Sumber: SPSS $25 . \overline{0}$

Tabel 5 menunjukkan bahwa semua indikator variabel Independen yaitu General Trust, Ability, Benevolence dan Integrity memiliki rata-rata diatas 3.2. Hal ini berarti sebagian besar responden menilai positif terhadap faktor Trust in Governmentdalam Tax Avoidance. Walaupun ada ketidak setujuan terkait faktor Trust in Government terhadap Tax Avoidance, hal ini hanya pada tingkatan "Kurang Setuju" dimana adanya sedikit

keyakinan terhadap dampak Trust in Government.

\section{Hasil Uji Asumsi Klasik \\ Uji Normalitas}

Uji Normalitas bertujuan untuk menguji apakah dalam model regresi, variabel penggangu atau residual memiliki distribusi normal. Pada penelitian ini Uji Normalitas menggunakan uji One-Sample Kolmogorov Smirnov Test.

Tabel 6

Hasil Uji Normalitas 1

One-Sample Kolmogorov-Smirnov Test

\begin{tabular}{llr} 
& & Tax Avoidance \\
\hline N & & 80 \\
\hline Normal Parameters & Mean & .5725 \\
\cline { 2 - 3 } & Std. Deviation & 1.97763 \\
\hline Most Extreme Differences & Absolute & .357 \\
\cline { 2 - 3 } & Positive & .357 \\
\cline { 2 - 3 } & Negative & -.323 \\
\hline Test Statistic & & .357 \\
\hline Asymp. Sig. (2-tailed) & & $.000^{\mathrm{C}}$ \\
\hline
\end{tabular}

Sumber: SPSS 25.0
a. Test distribution is Normal.
b. Calculated from data.
c. Lilliefors Significance Correction.

Berdasarkan tabel 6, hasil signifikansi uji residual tidak terdistribusi secara normal normalitas diatas menunjukkan hasil $0.000<$ langkah yang harus dilakukan oleh peneliti 0.05 hal ini berarti data residual tidak adalah melakukan transformasi data terdistribusi secara normal, karena tingkat menggunakan Lisrel 9.0. signifikansi dibawah 0,05. Dikarenakan data

\section{Tabel 7}

Hasil Uji Normalitas 2

One-Sample Kolmogorov-Smirnov Test

\begin{tabular}{llr} 
& & Tax Avoidance \\
\hline $\mathrm{N}$ & & 80 \\
\hline Normal Parameters & & Mean \\
\cline { 2 - 3 } & Std. Deviation & .59545 \\
\hline Most Extreme Differences & Absolute & 2.336082 \\
\cline { 2 - 3 } & Positive & .072 \\
\cline { 2 - 3 } & Negative & .067 \\
\hline
\end{tabular}




\begin{tabular}{lr}
\hline Test Statistic & .072 \\
\hline Asymp. Sig. (2-tailed) & $.200^{\mathrm{c}, \mathrm{d}}$ \\
\hline
\end{tabular}

a. Test distribution is Normal.

b. Calculated from data.

c. Lilliefors Significance Correction.

d. This is a lower bound of the true significance.

\section{Sumber: SPSS 25.0}

Berdasarkan tabel 7, hasil signifikansi uji normalitas diatas menunjukkan hasil $0.200>$ 0.05 hal ini berarti data residual terdistribusi secara normal, karena tingkat signifikansi diatas 0,05 .

\section{Uji Multikolinearitas}

Uji multikolinearitas bertujuan untuk menguji apakah model regresi ditemukan adanya korelasi antar variable bebas (independen).

\begin{tabular}{|c|c|c|c|c|c|c|c|c|}
\hline \multirow[b]{3}{*}{ Model } & \multicolumn{8}{|c|}{$\begin{array}{c}\text { Tabel } 8 \\
\text { Hasil Uji Multikolinearitas } \\
\text { Coefficients }^{\mathrm{a}}\end{array}$} \\
\hline & & \multicolumn{2}{|c|}{$\begin{array}{l}\text { Unstandardized } \\
\text { Coefficients }\end{array}$} & \multirow{2}{*}{$\begin{array}{c}\text { Standardize } \\
d \\
\text { Coefficients } \\
\\
\text { Beta } \\
\end{array}$} & \multirow[b]{2}{*}{$\mathrm{t}$} & \multirow[b]{2}{*}{ Sig. } & \multicolumn{2}{|c|}{$\begin{array}{c}\text { Collinearity } \\
\text { Statistics }\end{array}$} \\
\hline & & B & Std. Error & & & & $\begin{array}{c}\text { Toleranc } \\
\mathrm{e}\end{array}$ & VIF \\
\hline 1 & (Constant) & 9.788 & 1.297 & & 7.549 & .000 & & \\
\hline & General & -1.419 & .509 & -.362 & -2.790 & .007 & .287 & 3.489 \\
\hline & Ability & -.946 & .463 & -.272 & -2.041 & .045 & .271 & 3.685 \\
\hline & $\begin{array}{l}\text { Benevolenc } \\
\text { e }\end{array}$ & -.982 & .469 & -.266 & -2.092 & .040 & .299 & 3.347 \\
\hline & Integrity & .604 & .351 & .130 & 1.718 & .090 & .843 & 1.186 \\
\hline
\end{tabular}

a. Dependent Variable: Tax Avoidance

Sumber: SPSS 25.0

Nilai Cutoff yang umum dipakai untuk menunjukan adanya multikolinearitas adalah nilai Tolerance $\leq 0,10$ atau sama dengan nilai VIF $\geq 10$. Berdasarkan tabel 8nilai Tolerance semua variabel diatas $\leq 0,10$ sehingga tidak terjadi multikolinearitas

\section{Uji Heteroskedastisitas}

Uji Heteroskedastisitas bertujuan menguji apakah model regresi terjadi ketidak variance dari residual satu pengamatan ke pengamatan yang lain.

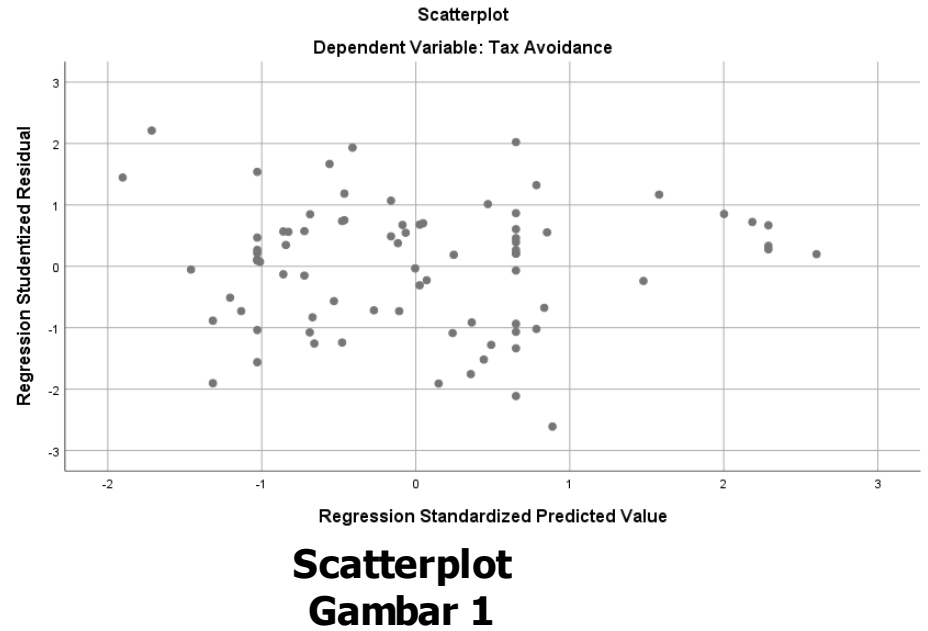

Sumber: SPSS 25.0 


\section{Berdasarkan Gambar 1, hasil Analisa Regresi menunjukkan bahwa titk-titik data tidak membentu pola tertentu dan data menyebar di atas dan di bawah angka 0 pada sumbu Y. Oleh karena itu dapat disimpulkan bahwa tidak terjadi gangguan asumsi heteroskedastisitas sehingga model regresi ini sudah baik. \\ Tabel 6 \\ Hasil Uji Koefisien Determinasi}

\begin{tabular}{ll|r|r|r|r} 
& \multicolumn{5}{c}{ Model Summary $^{\text {b }}$} \\
Model & $\mathrm{R}$ & R Square & \multicolumn{1}{c}{$\begin{array}{c}\text { Adjusted R } \\
\text { Square }\end{array}$} & $\begin{array}{c}\text { Std. Error of } \\
\text { the Estimate }\end{array}$ & Durbin-Watson \\
\hline 1 & $.799^{\mathrm{a}}$ & .639 & .620 & 1.440525 & 1.547 \\
\hline
\end{tabular}

a. Predictors: (Constant), Integrity, General, Benevolence, Ability

b. Dependent Variable: Tax Avoidance

\section{Sumber: SPSS 25.0}

Dari tabel di atas, dapat dilihat bahwa koefisien ( $r$ ) yaitu sebesar 0.799. nilai tersebut menunjukkan bahwa korelasi atau hubungan antara General Trust, Ability, Benevolence dan Integrity terhadap Tax Avoidance. Hal ini menunjukkan adanya hubungan yang kuat.

Sedangkan nilai Adjusted $R$ Square (koefisien determinasi) sebesar 0.620 yang berarti bahwa variasi variabel Tax Avoidance dapat djjelaskan oleh variabel General Trust, Ability, Benevolence dan Integrity adalah

sebesar 0.620 atau sebesar $62 \%$ sedangkan sisanya sebesar $38 \%$ dj̈elaskan oleh faktorfaktor lain yang tidak terdapat dalam penelitian ini.

\section{Uji F (Simultan)}

Uji F digunakan untuk menguji apakah secara bersama-sama seluruh variabel independen mempunyai pengaruh yang signifikan terhadap variabel dependen. Berikut

Tabel 9

Hasil Uji F

ANOVA $^{a}$

\begin{tabular}{|c|c|c|c|c|c|c|}
\hline & & $\begin{array}{l}\text { Sum of } \\
\text { Squares }\end{array}$ & $\mathrm{df}$ & Mean Square & $\mathrm{F}$ & Sig. \\
\hline \multirow[t]{3}{*}{1} & Regression & 275.492 & 4 & 68.873 & 33.190 & $.000^{b}$ \\
\hline & Residual & 155.633 & 75 & 2.075 & & \\
\hline & Total & 431.125 & 79 & & & \\
\hline
\end{tabular}

a. Dependent Variable: Tax Avoidance

b. Predictors: (Constant), Integrity, General, Benevolence, Ability

Sumber: SPSS 25.0

Berdasarkan hasil analisis regresi yang disajikan dalam Tabel di atas tampak bahwa dengan uji ANOVA atau $F$ test didapat $F$ hitung sebesar 33.190 dengan tingkat signifikan 0,000. Oleh karena probabilitas jauh lebih kecil dari 0,05 yang berarti $\mathrm{Ha}$ diterima yang dapat dikatakan bahwa General Trust, Ability, Benevolence dan Integrity secara bersamasama memiliki pengaruh terhadap Tax Avoidance.

\section{Uji t}

Berdasarkan tabel 10 ditemukan bahwa General Trust, Ability dan Benevolence berpengaruh secara negatif terhadap Tax Avoidance. Hal ini karena $p$-value dari ketiga variabel tersebut di bawah 0.05 sehingga dinyatakan adanya signifikansi dalam pengaruh terhadap Tax Avoidance. Namun hal ini tidak sejalan dengan variabel Integrity dimana terbukti memiliki pengaruh positif dan tidak signifikan (>0.05). Dengan kata lain, adanya kemungkinan semakin tinggi faktor Integrity, 
maka semakin perusahan melakukan penghindaran pajak.

\begin{tabular}{|c|c|c|c|c|c|c|c|}
\hline \multirow[b]{3}{*}{ Model } & \multirow{2}{*}{\multicolumn{2}{|c|}{$\begin{array}{l}\text { Unstandardized } \\
\text { Coefficients }\end{array}$}} & $\begin{array}{l}\text { Tabel } 10 \\
\text { tasil Uji t } \\
\text { efficients }\end{array}$ & \multirow[b]{3}{*}{$\mathrm{t}$} & \multirow[b]{3}{*}{ Sig. } & \multirow{2}{*}{\multicolumn{2}{|c|}{$\begin{array}{c}\text { Collinearity } \\
\text { Statistics }\end{array}$}} \\
\hline & & & $\begin{array}{l}\text { Standardiz } \\
\text { ed } \\
\text { Coefficient } \\
\text { s }\end{array}$ & & & & \\
\hline & B & Std. Error & Beta & & & ce & VIF \\
\hline $\begin{array}{ll}\quad \text { (Constant } \\
& \text { ) }\end{array}$ & 9.788 & 1.297 & & 7.549 & .000 & & \\
\hline General & -1.419 & .509 & -.362 & -2.790 & .007 & .287 & 3.489 \\
\hline Ability & -.946 & .463 & -.272 & -2.041 & .045 & .271 & 3.685 \\
\hline $\begin{array}{l}\text { Benevolen } \\
\text { ce }\end{array}$ & -.982 & .469 & -.266 & -2.092 & .040 & .299 & 3.347 \\
\hline Integrity & .604 & .351 & .130 & 1.718 & .090 & .843 & 1.186 \\
\hline
\end{tabular}

a. Dependent Variable: Tax Avoidance

\section{Hasil dan Pembahasan \\ Pengaruh General Trust terhadap Tax Avoidance}

Berdasarkan hasil empiris, ditemukan bahwa General Trust berpengaruh secara negatif terhadap Tax Avoidance. Hal ini berarti semakin tinggi General Trust, maka semakin rendah tindakan penghindaran pajak yang dilakukan oleh perusahaan. Hal ini memperkuat bahwa trust merupakan hal yang penting bagi para wajib pajak badan karena membentuk kesan yang baik terhadap reputasi Dirjen Pajak. Karena bagi semua wajib pajak, pajak merupakan beban bagi mereka sehingga kebermanfaatan pajak terhadap masyarakat akan seiring dengan tingkat reputasi Dirjen Pajak.

\section{Pengaruh Ability terhadap Tax Avoidance}

Berdasarkan hasil empiris, ditemukan bahwa Ability berpengaruh secara negatif terhadap Tax Avoidance. Hal ini berarti semakin tinggi Ability, maka semakin rendah tindakan penghindaran pajak yang dilakukan oleh perusahaan. Hal ini sesuai dengan penelitian Pahala, et.al (2012), yang menyatakan faktor kompetensi menjadi indikator kepuasan wajib pajak. Kompetensi yang baik akan memudahkan pelayanan pajak dan penyampaian informasi pajak didistribusikan dengan baik kepada para wajib pajak. Kejelasan wajib pajak terhadap peraturan pajak yang berlaku akan menghindari mereka untuk melakukan penghindaran pajak

\section{Pengaruh Benevolence terhadap Tax Avoidance}

Berdasarkan hasil empiris, ditemukan bahwa Benevolence berpengaruh secara negatif terhadap Tax Avoidance. Hal ini berarti semakin tinggi Benevolence, maka semakin rendah tindakan penghindaran pajak yang dilakukan oleh perusahaan. Hal ini sesuai dengan Mahmudi (2007), yang menjelaskan aspek Benevolence pemerintah yaitu meningkatkan kesejahteraan masyarakat. Motivasi tersebut akan terlihat dalam kualitas pelayanan pajak dan manfaat pajak yang dirasakan oleh para wajib pajak. Semakin baiknya kualitas pelayanan dan sinkronisasi manfaat pajak terhadap kebutuhan wajib pajak, maka menggambarkan adanya hubungan mutualisme antara beban pajak dengan hasil pengelolaan dana pemerintah yang bersumber dari pajak. Hubungan yang sedemikian dapat meningkatkan kepatuhan pajak bagi wajib pajak.

\section{Pengaruh Integrity terhadap Tax Avoidance}

Berdasarkan hasil empiris, ditemukan bahwa Integrity tidak berpengaruh terhadap Tax Avoidance. Hal ini menunjukkan bahwa 
integritas para fiskus dalam kesesuaian dengan peraturan perpajakan bersifat abstrak. Dinyatakan sedemikian, karena bergantung pada pandangan atas penafsiran peraturan perpajakan terkait kasus pajak. Hasil juga menunjukkan adanya pengaruh positif dengan koefisien sebesar 0.604. Hal ini menunjukkan bahwa adanya kekhawatiran para wajib pajak badan akan adanya ekstensifikasi pajak terhadap perusahaan ketika fiskus memeriksa sesuai dengan peraturan perpajakan. Ekstensifikasi pajak menimbulkan potensi beban pajak tambahan bagi perusahaan sehingga wajib pajak akan cenderung melakukan berbagai macam pendekatan penghindaran pajak agar terminimalisasinya beban perusahaan.

\section{Simpulan}

Hasil penelitian menunjukkan bahwa General Trust, Abilty dan Benevolence berpengaruh secara negatif terhadap Tax Avoidance. General Trust menunjukkan adanya kesan terhadap reputasi Dirjen Pajak yang sudah terbentuk selama ini. Ability menunjukkan tingkat kompetensi fiskus dalam mendistribusikan pelayanan dan informasi pajak dengan baik dan benar. Benevolence menggambarkan terpenuhinya tanggung jawab pemerintah terhadap kesejahteraan masyarakat. Ketiga hal ini dirasakan faktor yang nyata bagi para wajib pajak agar mereka patuh terhadap kewajiban pajak. Namun, faktor Integrity menunjukkan tidak signifikan karena tidak dapat diukur dengan pasti oleh wajib pajak. Malah faktor Integrity terkesan sebagai pisau bermata dua dimana dapat menunjukkan kejujuran fiskus dalam memberikan pelayanan atau kengototan fiskus agar beban pajak WP badan dapat sesuai dengan Peraturan Perpajakan.

Hasil penelitian ini dapat memberikan implikasi bagi Dirjen Pajak untuk meningkatkan pengungkapan informasi terkait manfaat pajak bagi masyarakat sehingga Dirjen Pajak dapat dianggap sebagai Wealth Agent bagi semua Wajib Pajak. Selain itu, perlu adanya penilaian publik atas kinerja fiskus atau KPP sehingga dapat memetakan citra Dirjen Pajak di mata masyarakat untuk perbaikan berkelanjutan.

Untuk penelitian selanjutnya, penelitian dapat dikembangkan faktor Social Norm terhadap penghindaran pajak. Hal ini karena faktor lingkungan sosial dapat memberikan dorongan yang kuat bagi pribadi maupun perusahaan untuk bersikap terkait dengan penghindaran pajak.

\section{Daftar Pustaka}

Afzal H., Khan, M.A., Rehman, K., Ali, I. \& Wajahat, S. (2010). Consumer's Trust in the Brand: Can it Be Built Through Brand Reputation, Brand Competence and Brand Predictability. International Business Research, 3(1), 43-51.

Chen, S., Chen, X., Cheng, Q. \& Shevlin, T. (2010). Are family firms more or less tax aggressive? Journal of Financial Economic, 95(1):41-61.

Creed, W.E.D. and Miles, R.E., Eds. (1996) Trust in Organizations: A Conceptual Framework. Sage Publications, London.

Darmin Nasution (2015). Darmin: Diperlukan 'Trust" dari Aparat dan Wajib Pajak. Diunduh dari http://bisniskeuangan. kompas.com/read /2015/04/09/143333226/DarminDiperlu kan.Trust.dari.Aparat.dan.Wajib.Pajak diposting pada tanggal 9 April 2015.

Freedman, M. \& Jaggi, B. (2005). Global warming, commitment to the Kyoto protocol, and accounting disclosures by the largest global public firms from polluting industries. The International Journal of Accounting, Vol. 40 No. 3, pp. 215-232.

Ghozali, I (2013). Aplikasi Analisis Multivariete dengan Program IBM SPSS 23. Edisi Kedelapan: Penerbit Universitas Diponegoro.

Hantoyo, S.S., Kertahadi \& Handayani, S.R. (2016), Pengaruh Penghindaran Pajak dan Sanksi Perpajakan terhadap Kepatuhan Wajib Pajak: Studi pada Wajib Pajak di Kantor Pelayanan Pajak Pratama Tegal. Jurnal Perpajakan (JEJAK), 9(1), 1-7. 
Hetherington, M. (2005). Why Trust Matters: Declining Political Trust and the Demise of American Liberalism. Princeton, NJ: Princeton University Press.

Jimenez, P.D. (2013). Tax Compliance in a Social Setting : The Influence of Norms, Perceptions of Fairness, and Trust in Government on Taxpayer Compliance. Dissertation : University of North Texas.

Jokowi (2016).Presiden: Animo Amnesti Pajak Jadi Momentum Perbaikan Sistem Perpajakan. Diunduh dari https://www. beritamoneter.com/preside n-animo-amnesti-pajak-jadi-momentumperbaikan-sistem-perpajakan/ yang diposting pada tanggal 29 September 2016.

Kim, E., dan Tadisina, S., (2003),Customer's Initial Trust in E-Business: How to Measure Customer's Initial Trust, Proceedings of Ninth Americas Conference on Information Systems, pp. 35-41.

Komite Pengawasan Pajak (2019). Jumlah Pengaduan Pajak Menurun Selama Dua Tahun Terakhir. Diunduh dari http://komwasperpajakan.depkeu.go.id/ Berita/Details/1122 yang diposting pada tanggal 10 Januari 2019.

Lewis, J.D. \& Weigert, A. (1985). Trust as a social reality. Social Forces, 63(3), 96785.

Lindblom, C. (1994). The Implications of Organizational Legitimacy for Corporate Social Performance and Disclosure. Critical Perspectives on Accounting Conference, New York.

Mahmudi (2007). Manajemen Kinerja Sektor Publik. YPKN, Yogyakarta.

Mayer, R. C., J. H. Davis, and F. D. Schoorman. (1995). An Integrative Model of Organizational Trust. Academy of Management Review 20 (3): 709-734
Nazier (2016). Masyarakat Mau Isi SPT Tingkat Kepatuhan Bayar pajak RI 56\%.

Diunduh dari

http://finance.detik.com/ekonomibisnis/3149073/masyarakat-mau-isi-spttingkat-kepatuhan-bayar-pajak-ri-56 diposting pada tanggal 23 Februari 2016.

Pahala, I., Hasanah.,N. \& Sari, I.P. (2013). Pengaruh Kompetensi Pegawai Pajak dan Kualitas Pelayanan Pajak Terhadap Kepuasan Wajib Pajak Pada Kantor Pelayanan Pajak Pratama Jakarta Kota .Jurnal Prosiding Simposium Nasional Perpajakan 4.

Siahaan, F.O.P. (2012). The Influence of Tax Fairness and Communication on Voluntary Compliance : Trust as an Intervening Variable. International Journal of Business and Social Science, 3(21), 191 - 198.

Sitardja, M., \& Dwimulyani, S. (2016). Analysis about The Influences of Good Public Governance, Trust toward Tax Compliance on Public Companies that listed in Indonesian Stock Exchange. OIDA International Journal of Sustainable Development, 9(9), 35-42.

Suandy, E. (2016). Perencanaan Pajak Edisi 6. Penerbit Salemba Empat.

Undang-Undang No 16 Tahun 2009. Ketentuan Umum dan Tata Cara Perpajakan.

http://www.setpp.kemenkeu.go.id/statistik 